\title{
Enhanced Growth of ZDDP-Based Tribofilms on Laser-Interference Patterned Cylinder Roller Bearings
}

\author{
Chia-Jui Hsu ${ }^{1, *}$ (D) , Andreas Stratmann ${ }^{2}$ (), Andreas Rosenkranz ${ }^{3}$ and Carsten Gachot ${ }^{4}$ \\ 1 Chair of Functional Materials, Saarland University, 66123 Saarbrücken, Germany \\ 2 Institute for Machine Elements and Machine Design, 52062 RWTH Aachen, Aachen, Germany; \\ andreas.stratmann@ime.rwth-aachen.de \\ 3 Center for Memory and Recording Research, University of California, San Diego, La Jolla, CA 92093, USA; \\ arosenkranz@ucsd.edu \\ 4 Institute for Engineering Design and Logistics Engineering, TU Wien, 1060 Vienna, Austria; \\ carsten.gachot@tuwien.ac.at \\ * Correspondence: chiajui.hsu@uni-saarland.de; Tel.: +49-681302-70543
}

Received: 26 August 2017; Accepted: 13 September 2017; Published: 25 September 2017

\begin{abstract}
Laser surface texturing has been successfully applied in the past to various machine elements in order to improve their tribological performance. In this study, direct laser interference patterning was used to produce periodic cross-like surface patterns on commercial cylinder roller bearings. The wear behavior of as-patterned bearings was studied by a modified FE8 test rig under boundary lubrication. A mineral oil (ISO VG 100) as a base oil additivated with $0.02 \mathrm{wt} \%$ zinc dialkyldithiophosphate (ZDDP) was used for the tribological tests which were performed under a Hertzian pressure of $1.92 \mathrm{GPa}$ and maintained at $80^{\circ} \mathrm{C}$ and $20 \mathrm{rpm}$ for $2 \mathrm{~h}$. The laser-patterned bearings showed a significantly reduced mass loss by two orders of magnitude compared to the unpatterned reference bearings. A closer look at the samples proved the formation of the characteristic blue-colored ZDDP tribofilm on top of the laser-induced topography maximum positions. Due to the higher contact pressure at the laser-induced peaks, the tribofilm formation was preferable at those positions thus protecting against wear. The laser patterns nearly remained unworn compared to the reference samples. A subsequent Raman analysis of the laser-patterned bearings clearly revealed the formation of zinc and iron sulfides as well as phosphates at the peak points.
\end{abstract}

Keywords: laser surface treatment; direct laser interference patterning; boundary lubrication; ZDDP; roller bearings

\section{Introduction}

In tribology, boundary lubrication is a lubrication regime which typically appears in the interfaces of gears, bearings, and piston rings, etc., for relatively low sliding speeds and rather high loads [1]. In this lubrication regime, the oil film thickness is generally significantly lower than the combined surface roughness of both rubbing partners, which can be reflected in a $\lambda$-parameter smaller than 1. As a consequence, the surface asperities play an important role since the load is mainly carried by those asperities. Wear occurs inevitably under boundary lubrication, and it is well known that the formation of an anti-wear tribolayer is the solution to protect the substrate and to prevent severe wear [2,3]. In terms of tribofilm formation, zinc dialkyldithiophosphate (ZDDP) can be named as a popular lubricant additive, which has been widely studied and utilized for more than 70 years due to its outstanding anti-wear performance and its additional multi-functional characteristics such as anti-corrosion and antioxidant properties. Those properties can help to provide protection against damage from wear and to extend the component's lifetime. In general, ZDDP tribofilms are described as blue and brown-colored patchy layers formed in the rubbing area [4]. Those layers are composed 
of, for example, iron sulfides and amorphous orthophosphates [5]. There are two ways to generate ZDDP reaction layers, either by thermal activation or tribomechanical reactions [6,7]. In this context, Bancroft et al. demonstrated that tribomechanically induced tribofilms are more stable against wear [8]. Gosvami et al. proved that the tribofilm formation is pressure-induced and not thermally induced. [9]. Furthermore, Gachot et al. proved that the blue-colored tribofilm areas contain a high amount of phosphates and zinc sulfides [10]. Even though the mechanism of the ZDDP tribofilm formation and the detailed reaction paths are still not clear and well understood, there is a consensus that the presence of the tribofilm can help to protect the rubbing surface, thus improving the friction and wear performance [11].

Despite the aforementioned beneficial effects, there are more and more restrictions for the usage of ZDDP because phosphorous and sulphur oxides reduce the effective lifetime of exhaust catalysts [12]. It is necessary to introduce other methods that can reduce both the wear and the usage of ZDDP. Lately, laser surface texturing (LST) has become a powerful tool for surface modification due to its ability to precisely tailor materials [13-15]. Lasers using pulses with short and ultra-short pulse duration such as nano- and femtoseconds have been typically used in this context because of their high flexibility towards various materials. However, one shortcoming that can be named is the processing time. Complex pattern geometries require a relatively long time to be fabricated. In addition to that, in order to modify large surfaces, the individual laser pulses need to be overlapped, which might lead to slight inhomogeneities in the overlapping areas [3]. Therefore, direct laser interference patterning (DLIP) was developed to produce complex patterns on a relatively large area in just a single laser shot. DLIP ensures a time-efficient and fast surface modification by superimposing two or more coherent laser beams $[12,16]$. This technique produces periodic patterns onto the surface of interest and has been proven to give characteristic patterns for versatile functions, such as friction and wear reduction [17-19], reduction of the electrical contact resistance [20], and modifications of wetting properties [21,22]. For the frictional modification induced by DLIP, Gachot et al. suggested that the surface geometry is the most significant influencing factor [19]. Rosenkranz et al. demonstrated that dot-like patterns on the surface of bearings produced by three beams interference perform well and show a wear reduction of $83 \%$ compared to the reference state. The patterns were able to store wear particles in the topographic valleys, thus reducing abrasive wear and therefore lowering the wear volume. Even though DLIP would create an additional artificial roughness on the contact surface, which might lead to an increased contact pressure, the ability to store wear particles seems to be promising in terms of wear reduction [23].

The aim of the present research study is to investigate the effects of specific surface patterns created by DLIP on the wear performance of highly loaded cylinder roller bearings under boundary lubrication, as well as the interaction between the resulting surfaces patterns and the ZDDP additivated oil. Moreover, the formation of the tribolayer and its properties are demonstrated and discussed.

\section{Experiments}

\subsection{FE8 Test Rig}

In the present study, cylinder roller bearings (Type 81212), consisting of two washers, a cage, and several cylinder rollers made of $100 \mathrm{Cr}_{6}$ bearing steel (AISI 52100) were tested in a modified FE8 test rig corresponding to DIN 51819-3. A mineral oil of class ISO VG 100 was used as base oil and mixed with ZDDP additive using a concentration of $0.02 \mathrm{wt} \%$ phosphorus and short secondary chains (C3-C8). During the test, sufficient lubricant was supplied to the contact area by a pumping system. The rotational speed was set to $20 \mathrm{rpm}$. The test was run at $80^{\circ} \mathrm{C}$ with an axial load of $80 \mathrm{kN}$, which corresponds to a Hertzian pressure of $1.92 \mathrm{GPa}$. The total testing time was $2 \mathrm{~h}$. The lubricating condition was calculated as boundary lubrication according to Dowson et al. [24], with a minimum film height $h_{0}=4.88 \mathrm{~nm}$. After the test, the surface was cleaned by using benzene and isopropanol to 
remove the residual lubricant, abrasives, and contaminants. More details regarding the test rig and testing parameters can be found elsewhere [25].

\subsection{Direct Laser Interference Patterning (DLIP)}

DLIP is a surface treatment conducted by applying interfering sub-beams onto the target samples which can produce a relatively large patterning area in a short period of time. A pulsed Nd:YAG laser (Quanta Ray Pro 290, Spectra Physics, Santa Clara, CA, USA) was used providing a wavelength of $532 \mathrm{~nm}$. The repetition rate of the laser was $10 \mathrm{~Hz}$ with pulse duration of $10 \mathrm{~ns}$. The peak power of the laser was $0.83 \mathrm{~J} \cdot \mathrm{cm}^{-2}$. Figure 1 shows the experimental setup needed to realize DLIP.

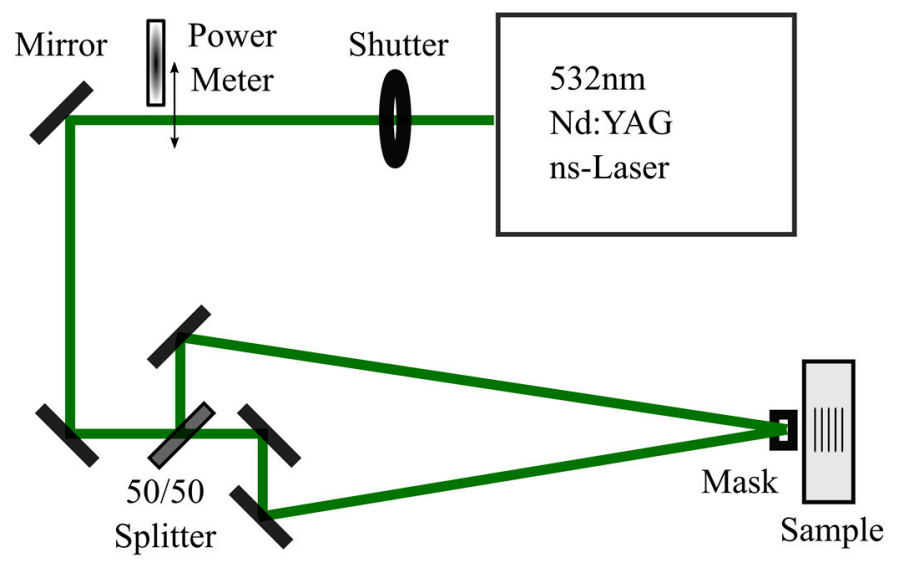

Figure 1. Schematic diagram of direct laser interference patterning (DLIP) in order to realize two-beam interference.

The primary beam (circular beam of around $10 \mathrm{~mm}$ in diameter) was then controlled by a mechanical shutter system (VS25S2ZMO, Uniblitz Electronic, Rochestern, NY, USA), allowing only one pulse passing by for each shot. The laser power was measured by a pyrometric power meter (EnergyMax Sensors, Coherent, Palo Alto, CA, USA). The primary beam was split into two sub-beams by using a beam splitter. Afterwards, highly reflective mirrors were used to superimpose the sub-beams onto the sample. Two-beam interference generated a periodic line-like surface topography. By changing the incident angle between the two sub-beams the periodicities could be modified in a range from 1 to $30 \mu \mathrm{m}$. Finally, the overlapping area was selected and shaped as $1 \times 1 \mathrm{~mm}^{2}$ by applying a squared refractory mask. Therefore, the line-like pattern was formed on the surface of the bearing washer. In addition, the position of the sample was controlled by a programmable $x-y$ stage. In this study, the bearing washer was rotated by $90^{\circ}$ after the first patterning step in order to produce cross-like surface patterns.

\subsection{Characterization}

Surface chemistry was examined by Raman spectroscopy (confocal Raman microscope, Renishaw, Wotton-under-Edge, UK) equipped with a grating of 2400 lines $\mathrm{mm}^{-1}$ and a spectral resolution up to $1.2 \mathrm{~cm}^{-1}$. A laser producing an excitation wavelength of $532 \mathrm{~nm}$ was used to provide a power of $500 \mathrm{~mW}$. The laser power was set as $10 \%$ to prevent thermal damage of the tribolayer. The spectrum between 200 and $1300 \mathrm{~cm}^{-1}$ was obtained using an acquisition time of $200 \mathrm{~s}$. In addition, the overall morphology and topography of the laser-patterned samples and the wear tracks were imaged using laser scanning microscopy (LSM, LEXT OLS4100, Tokyo, Japan) and white light interferometry (WLI, Zygo NewView 7300, Harpenden, UK). The wear loss of the bearing was evaluated after the tribological experiments using a precision balance (CP324S Sartorius, Elk Grove Village, IL, USA). 


\section{Results and Discussions}

\subsection{Surface topography}

The surface topography of the bearing washer after DLIP is shown in Figure 2, which clearly shows the cross-like patterns with a mean structural depth (peak to valley) of $1.2 \mu \mathrm{m}$ and a lateral periodicity of $30 \mu \mathrm{m}$. In a previous review paper summarizing the effects of surface patterning on friction and wear, it was suggested that the structural depth of the laser pattern should be in the micron range for boundary lubrication [3]. DLIP typically produces pattern geometries with a mean structural depth of roughly 1-2 $\mu \mathrm{m}$ which makes DLIP an interesting approach to influence the tribological performance under boundary lubrication. The roughness parameters of the reference and patterned surfaces are summarized in Table 1 , including values of $R_{\mathrm{rms}}, R_{\mathrm{tm}}$, and $R_{\mathrm{sk}}$. It can be clearly seen that the surface roughness increased after DLIP because $R_{\text {rms }}$ increases from 0.07 to $0.3 \mu \mathrm{m}$. The value $R_{\mathrm{tm}}$ (mean of maximum peak to valley height) can be used to evaluate the performance of the patterned surface showing the depth below the contact surface which will store lubricant and supply lubricant to the contact area when needed. Moreover, the value $R_{\text {sk }}$ (skewness) also provides information about the lubricant preservation. For positive $R_{\mathrm{sk}}$ values, a high amount of valleys can be found indicating a larger capacity to store lubricant [26]. Based upon the presented values, the surface roughness increases after DLIP. Although a possible storage of lubricant can be ensured, the induced surface topography by DLIP might increase friction and wear due to edge effects and stress concentrations.

Table 1. Summary of the roughness parameters of the reference and the laser-patterned surface, prior to and after rubbing $\left(R_{\mathrm{rms}}\right.$ : root mean square; $R_{\mathrm{tm}}$ : mean of maximum peak to valley height; $R_{\mathrm{sk}}$ : skewness).

\begin{tabular}{|c|c|c|c|c|c|c|}
\hline & \multicolumn{3}{|c|}{ Prior to Rubbing } & \multicolumn{3}{|c|}{ After Rubbing } \\
\hline & $R_{\mathrm{rms}} / \mu \mathrm{m}$ & $R_{\mathrm{tm}} / \mu \mathrm{m}$ & $R_{\mathrm{sk}}$ & $R_{\mathrm{rms}} / \mu \mathrm{m}$ & $R_{\mathrm{tm}} / \mu \mathrm{m}$ & $R_{\mathrm{sk}}$ \\
\hline Reference & $0.07 \pm 0.01$ & $0.28 \pm 0.05$ & $-0.60 \pm 0.05$ & $0.08 \pm 0.01$ & $0.03 \pm 0.01$ & $-0.88 \pm 0.27$ \\
\hline Cross-patterned & $0.30 \pm 0.02$ & $1.39 \pm 0.07$ & $0.15 \pm 0.13$ & $0.20 \pm 0.01$ & $0.81 \pm 0.07$ & $-0.23 \pm 0.04$ \\
\hline
\end{tabular}

In this case, the formation of the tribolayer would be the solution to prevent severe wear damage. As long as an anti-wear tribofilm is formed on the contact surface, the harmful abrasive particles would not be generated, thus protecting the surface from wear.

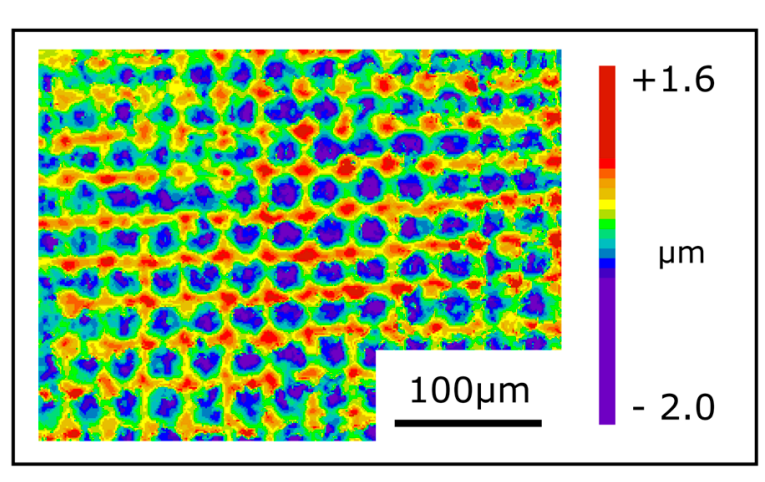

(a)

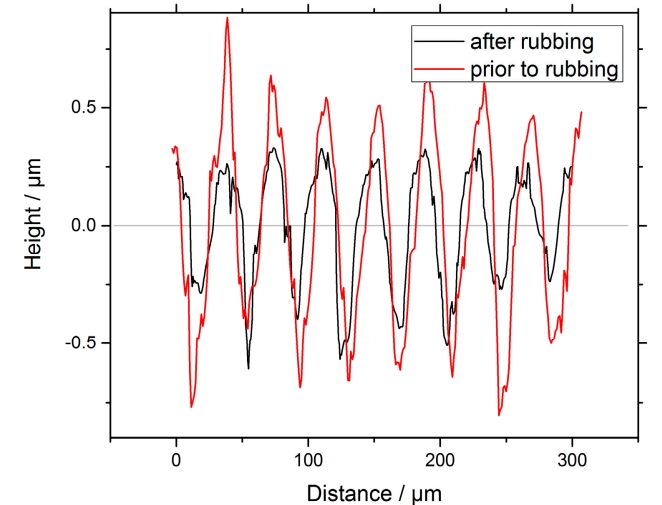

(b)

Figure 2. Surface morphology (a) and surface profile (b) of the laser-patterned cross-like structure with a periodicity of $30 \mu \mathrm{m}$ imaged by white light interferometry (WLI). In (b), a comparison of the surface profile prior to and after rubbing is presented. 


\subsection{Tribological Performance}

In Table 1, the roughness parameters prior to and after rubbing are shown in order to evaluate the effect of DLIP on the tribological performance. After rubbing, the $R_{\mathrm{tm}}$ value also decreases from 1.39 to $0.81 \mu \mathrm{m}$, indicating unpreventable wear damage. However, the value is still much higher than the respective value of the untreated reference sample. Additionally, it should be emphasized that the periodical cross-like patterns remain intact with a reduced structural depth (approximately $40 \%$ of the initial value) after rubbing. This effect can be well seen in Figure $2 b$. Both results show that the capacity of DLIP to store lubricant and to trap abrasive particles remains, even after $2 \mathrm{~h}$ of testing under severe conditions. Furthermore, $R_{\mathrm{sk}}$ shifts from positive to negative values, indicating a more plateau-like topography along the rubbed surface. According to the decrease of both $R_{\mathrm{tm}}$ and $R_{\mathrm{sk}}$, it can be concluded that the sharp peaks were flattened to blunt asperities during rubbing, thus leading to a better load-carrying capacity.

The coefficient of friction was measured during rubbing. The average coefficient of friction (COF) of the reference sample is 0.14 , whereas the value for the cross-patterned surface is about 0.1 . The COF of the DLIP sample decreases approximately $30 \%$, and the measurement of wear mass losses was further introduced. In Table 2, the respective wear losses of the washer and the roller set (reference and laser-patterned) are presented. The mass loss was evaluated by comparing the weight of the washer and the roller set prior to and after rubbing. For the reference washer without DLIP, it can be seen that after two hours a rather large mass loss of $62.5 \mathrm{mg}$ can be measured. In contrast to that, the wear damage of the laser-patterned surface can be barely seen. It can be stated that the respective mass loss could be reduced by two orders of magnitude. In addition, for the roller set, the same experimental trends in terms of mass loss can be detected. This implies that DLIP offers the possibility of preventing the bearing from severe wear, which could be attributed to the topography due to abrasive particles and insufficient lubricant supply. Moreover, the formation of ZDDP tribofilm which was mentioned earlier prevents direct contact between two metal surfaces thus decreasing the damage from wear.

Table 2. Summary of the total mass loss of the washer and roller set of the roller bearings for the reference and laser-patterned sample.

\begin{tabular}{ccc}
\hline & Washer Mass Loss $\Delta \mathrm{m} / \mathbf{m g}$ & Roller Set Mass Loss $\Delta m / \mathbf{m g}$ \\
\hline Reference & 62.5 & 80.5 \\
Cross-patterned & 0.1 & 0.1 \\
\hline
\end{tabular}

In Figure 3, the surface topography after rubbing imaged by optical and laser scanning microscopy is depicted. It can be observed that the cross-like structure remains intact with a reduced mean depth of $0.9 \mu \mathrm{m}$. Furthermore, it should be mentioned that $P_{1}$ marks a blue spot in Figure $3 a, b$. By comparing both figures, the blue spots typically formed by the tribofilm can be found in the topographic maximum positions. It is worth mentioning that a second spot, $\mathrm{P}_{2}$, was marked in the figures, representing the area of the topographic minimum position. In those regions, there is no sign of tribofilm formation in the topographic valleys ( $\mathrm{P}_{2}$ in Figure $\left.3 \mathrm{a}, \mathrm{b}\right)$. Since ZDDP tribolayers can be described as a mixture of blue- and brown-colored films distributed in the contact region [4,27], the blue tribofilm can be traced back to pressure and sliding friction. Consequently, the blue spots appearing in those figures can be attributed to the ZDDP tribofilm, which is the key feature to provide protection of the contact surfaces against wear $[8,11]$. Finally, those two points $\left(\mathrm{P}_{1}\right.$ and $\left.\mathrm{P}_{2}\right)$ were selected to analyze the surface chemistry by Raman spectroscopy dependent on the surface topography (topographic maximum and minimum positions). 


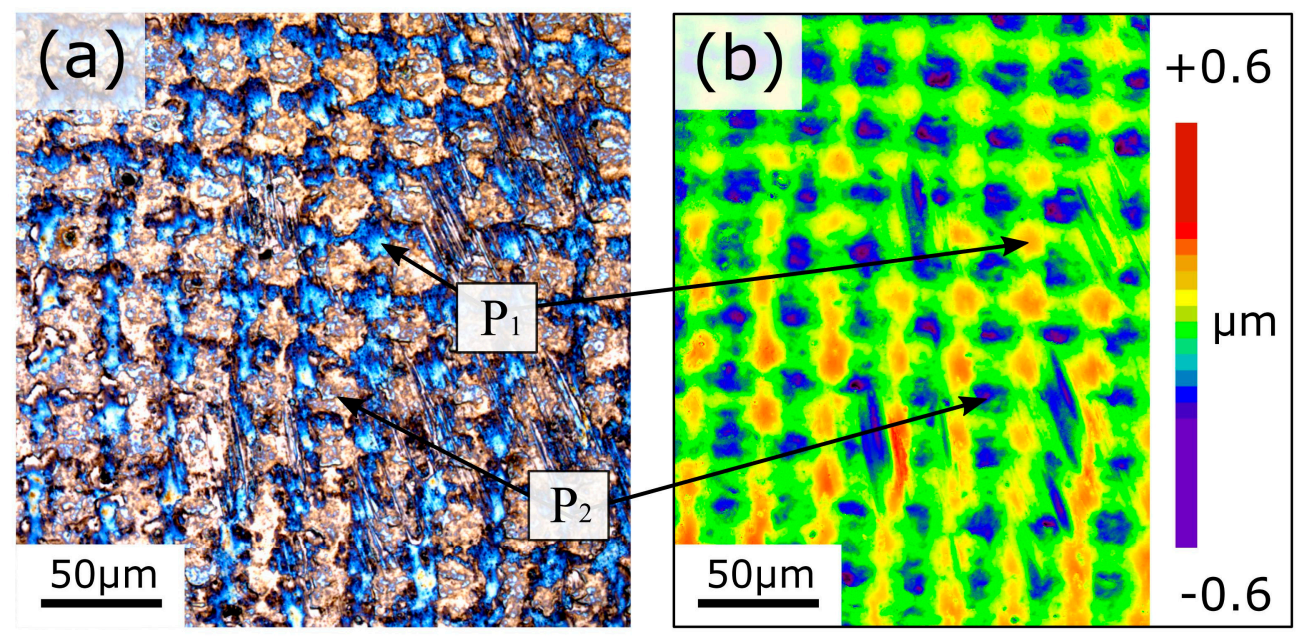

Figure 3. Surface topography after rubbing imaged by (a) optical microscopy and (b) laser scanning microscopy (LSM). $\mathrm{P}_{1}$ marks a position with blue-colored tribofilm on the top of patterns, whereas $\mathrm{P}_{2}$ highlights a region of valleys without blue color.

\subsection{Raman Spectroscopy}

The surface chemistry of the ZDDP tribofilms on the cross-like patterns was studied by Raman spectroscopy. In Figure 4, the corresponding Raman spectra for $\mathrm{P}_{1}$ and $\mathrm{P}_{2}$ are depicted. The spectrum measured at $\mathrm{P}_{1}$ shows pronounced peaks related to $\mathrm{Zn}-\mathrm{S}, \mathrm{Fe}-\mathrm{S}$, and $\mathrm{P}-\mathrm{O}$ at Raman shifts of 351, 386, and $965 \mathrm{~cm}^{-1}$ [28-30], whereas $\mathrm{P}_{2}$ reveals peaks related to $\mathrm{Fe}_{3} \mathrm{O}_{4}$ at 320 and $670 \mathrm{~cm}^{-1}$ [31]. The peaks assigned to $\mathrm{P}_{1}$ correlate well with the composition of ZDDP, which goes hand in hand with previously published results [10]. This in turn implies that the tribolayer was formed on top of the pattern induced by the increased contact pressure. As shown by Bancroft et al. [8], the pressure-induced tribofilms exhibit better tribological performance compared to the thermally induced films. Under tribological contact, the tribofilm grows faster due to the applied pressure [7]. The presence of the blue tribofilm appears only on top of the patterns, which significantly reduces the wear loss, and proves the pressure-induced film formation.

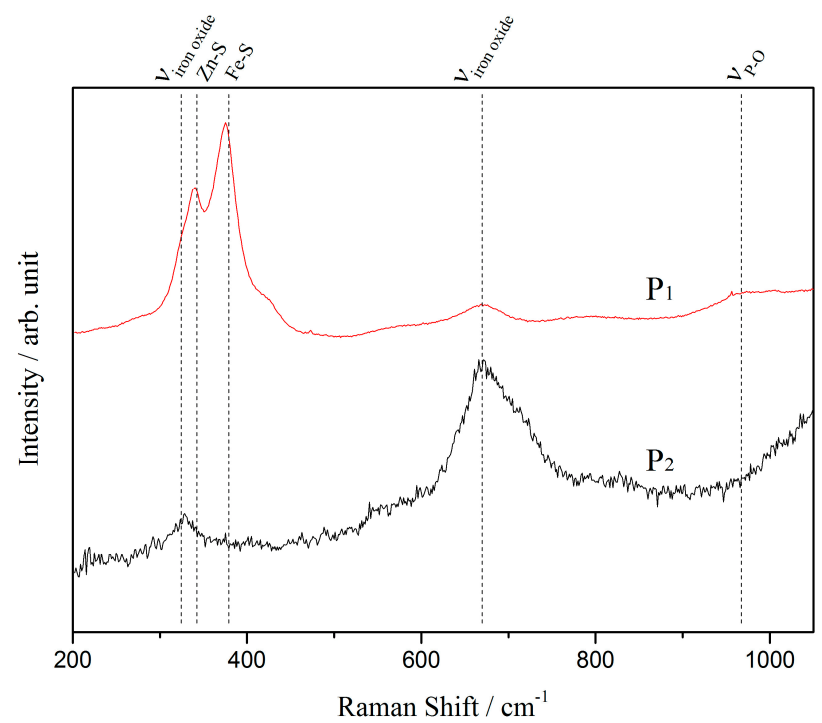

Figure 4. Raman spectra measured at $\mathrm{P}_{1}$ : blue-colored tribofilm on the topographical maximum of the patterns, and $\mathrm{P}_{2}$ : valley area of the patterns after rubbing. 


\section{Conclusions}

In this study, the effects of periodic cross-like patterns produced by DLIP on the tribological and wear performance of cylinder roller bearings were studied by using a modified FE8 test rig. The mass loss was evaluated by a precision balance and the topography was measured and described by WLI and LSM. Moreover, the surface chemistry was analyzed by Raman spectroscopy.

Topographic parameters such as $R_{\mathrm{tm}}$ and $R_{\mathrm{sk}}$ demonstrated that the periodic laser patterns, which are able to store lubricant and trap abrasive particles during rubbing, remain intact even after severe rubbing. The surface has no obvious wear marks, and the characteristic blue-colored tribolayer was only formed at the laser-induced topographic maximum positions of the patterned surface with the highest contact pressure, thus confirming the formation of a pressure-induced tribofilm. A subsequent Raman analysis clearly revealed peaks related to $\mathrm{Zn}-\mathrm{S}, \mathrm{Fe}-\mathrm{S}$, and $\mathrm{P}-\mathrm{O}$ in the Raman spectra typical for the blue-colored tribolayer. Because the successful tribofilm formation at the topographic maxima positions were in contact with the counter-body, the wear loss could be significantly decreased in comparison to the unpatterned reference sample.

Acknowledgments: The present work is supported by funding from the Deutsche Forschungsgemeinschaft (DFG) in the priority program SPP 1551 "Resource efficient design elements" (DFG, project: GA 1706/2-2). Volker Presser (Raman spectroscopy, Saarland University) is kindly acknowledged. Andreas Rosenkranz greatly acknowledges the Feodor Lynen Fellowship of the Alexander von Humboldt foundation.

Author Contributions: In this study, Chia-Jui Hsu and Carsten Gachot conceived and designed the experiments; Chia-Jui Hsu and Andreas Stratmann performed the experiments; Chia-Jui Hsu, Carsten Gachot, Andreas Stratmann and Andreas Rosenkranz analyzed and discussed the data as well as wrote the manuscript.

Conflicts of Interest: The authors declare no conflict of interest.

\section{References}

1. Hsu, S.M.; Gates, R.S. Boundary lubricating films: Formation and lubrication mechanism. Tribol. Int. 2005, 38, 305-312. [CrossRef]

2. Spikes, H.A. Boundary Lubrication and Boundary Films. Tribol. Ser. 1993, 25, 331-346.

3. Gachot, C.; Rosenkranz, A.; Hsu, S.M.; Costa, H.L. A critical assessment of surface texturing for friction and wear improvement. Wear 2017, 372-373, 21-41. [CrossRef]

4. Hsu, S.M. Boundary Lubrication of Materials. MRS Bull. 1991, 16, 54-58. [CrossRef]

5. Martin, J.M. Antiwear mechanisms of zinc dithiophosphate: A chemical hardness approach. Tribol. Lett. 1999, 6, 1-8. [CrossRef]

6. Fuller, M.; Bancroft, G.M.; Tan, K.H.; Yamaguchi, E.S.; Ryason, P.R.; Wiliermet, P.A. Chemical characterization of chemical and thermal films generated from neutral and basic ZDDPs using X-ray absorption spectroscopy. Tribol. Int. 1997, 30, 305-315. [CrossRef]

7. Fujita, H.; Spikes, H.A. The formation of zinc dithiophosphate antiwear films. Proc. Inst. Mech. Eng. Part J J. Eng. Tribol. 2004, 218, 265-278. [CrossRef]

8. Bancroft, G.M.; Kasrai, M.; Fuller, M.; Yin, Z.; Fyfe, K.; Tan, K.H. Mechanisms of tribochemical film formation: Stability of tribo- and thermally-generated ZDDP films. Tribol. Lett. 1997, 3, 47-51. [CrossRef]

9. Gosvami, N.N.; Bares, J.A.; Mangolini, F.; Konicek, A.R.; Yablon, D.G.; Carpick, R.W. Mechanisms of antiwear tribofilm growth revealed in situ by single-asperity sliding contacts. Science 2015, 348, 102-106. [CrossRef] [PubMed]

10. Gachot, C.; Hsu, C.; Suárez, S.; Grützmacher, P.; Rosenkranz, A.; Stratmann, A.; Jacobs, G. Microstructural and Chemical Characterization of the Tribolayer Formation in Highly Loaded Cylindrical Roller Thrust Bearings. Lubricants 2016, 4, 19. [CrossRef]

11. Spikes, H. The history and mechanisms of ZDDP. Tribol. Lett. 2004, 17, 469-489. [CrossRef]

12. Lasagni, A.; Holzapfel, C.; Weirich, T.; Mücklich, F. Laser interference metallurgy: A new method for periodic surface microstructure design on multilayered metallic thin films. Appl. Surf. Sci. 2007, 253, 8070-8074. [CrossRef]

13. Etsion, I.; Halperin, G.; Brizmer, V.; Kligerman, Y. Experimental investigation of laser surface textured parallel thrust bearings. Tribol. Lett. 2004, 17, 295-300. [CrossRef] 
14. Etsion, I. State of the Art in Laser Surface Texturing. J. Tribol. 2005, 127, 248. [CrossRef]

15. Li, X.; Bhushan, B. Micromechanical and tribological characterization of hard amorphous carbon coatings as thin as $5 \mathrm{~nm}$ for magnetic recording heads. Wear 1998, 220, 51-58. [CrossRef]

16. Mücklich, F.; Lasagni, A.; Daniel, C. Laser interference metallurgy-Periodic surface patterning and formation of intermetallics. Intermetallics 2005, 13, 437-442. [CrossRef]

17. Duarte, M.; Lasagni, A.; Giovanelli, R.; Narciso, J.; Louis, E.; Mücklich, F. Increasing lubricant film lifetime by grooving periodical patterns using laser interference metallurgy. Adv. Eng. Mater. 2008, 10, 554-558. [CrossRef]

18. Rosenkranz, A.; Jaeger, S.; Gachot, C.; Vogel, S.; Mücklich, F. Wear Behavior of Laser-Patterned Piston Rings in Squeeze Film Dampers. Adv. Eng. Mater. 2015, 17, 1208-1214. [CrossRef]

19. Gachot, C.; Rosenkranz, A.; Reinert, L.; Ramos-Moore, E.; Souza, N.; Müser, M.H.; Mücklich, F. Dry friction between laser-patterned surfaces: Role of alignment, structural wavelength and surface chemistry. Tribol. Lett. 2013, 49, 193-202. [CrossRef]

20. Trinh, K.E.; Tsipenyuk, A.; Varenberg, M.; Rosenkranz, A.; Souza, N.; Mücklich, F. Wear debris and electrical resistance in textured Sn-coated $\mathrm{Cu}$ contacts subjected to fretting. Wear 2015, 344-345, 86-98. [CrossRef]

21. Hans, M.; Müller, F.; Grandthyll, S.; Hüfner, S.; Mücklich, F. Anisotropic wetting of copper alloys induced by one-step laser micro-patterning. Appl. Surf. Sci. 2012, 263, 416-422. [CrossRef]

22. Grützmacher, P.G.; Rosenkranz, A.; Gachot, C. How to guide lubricants-Tailored laser surface patterns on stainless steel. Appl. Surf. Sci. 2016, 370, 59-66. [CrossRef]

23. Rosenkranz, A.; Stratmann, A.; Gachot, C.; Burghardt, G.; Jacobs, G.; Mücklich, F. Improved wear behavior of cylindrical roller thrust bearings by three-beam laser interference. Adv. Eng. Mater. 2016, 18, 854-862. [CrossRef]

24. Dowson, D.; Higginson, G.R.; Whitaker, A.V. Elasto-hydrodynamic Lubrication: A Survey of Isothermal Solutions. J. Mech. Eng. Sci. 1962, 4, 121-126. [CrossRef]

25. Stratmann, A.; Jacobs, G.; Hsu, C.J.; Gachot, C.; Burghardt, G. Antiwear tribofilm growth in rolling bearings under boundary lubrication conditions. Tribol. Int. 2017, 113, 43-49. [CrossRef]

26. Gadelmawla, E.S.; Koura, M.M.; Maksoud, T.M.A.; Elewa, I.M.; Soliman, H.H. Roughness parameters. J. Mater. Process. Technol. 2002, 123, 133-145. [CrossRef]

27. De Barros, M.I.; Bouchet, J.; Raoult, I.; Le Mogne, T.; Martin, J.M.; Kasrai, M.; Yamada, Y. Friction reduction by metal sulfides in boundary lubrication studied by XPS and XANES analyses. Wear 2003, 254, 863-870. [CrossRef]

28. Brafman, O.; Mitra, S.S. Raman effect in wurtzite- and zinc-blende-type ZnS single crystals. Phys. Rev. 1968, 171, 931-934. [CrossRef]

29. Ushioda, S. Raman scattering from phonons in iron pyrite (FeS2). Solid State Commun. 1972, 10, 307-310. [CrossRef]

30. Berkani, S.; Dassenoy, F.; Minfray, C.; Martin, J.M.; Cardon, H.; Montagnac, G.; Reynard, B. Structural changes in tribo-stressed zinc polyphosphates. Tribol. Lett. 2013, 51, 489-498. [CrossRef]

31. De Faria, D.L.A.; Silva, S.V.; de Oliveira, M.T. Raman microspectroscopy of some iron oxides and oxyhydroxides. J. Raman Spectrosc. 1997, 28, 873-878. [CrossRef]

(C) 2017 by the authors. Licensee MDPI, Basel, Switzerland. This article is an open access article distributed under the terms and conditions of the Creative Commons Attribution (CC BY) license (http:/ / creativecommons.org/licenses/by/4.0/). 